(c) Dereito Vol.28, n02:61-89 (Xullo-Decembro, 2019) • ISSN 1132-9947

\title{
LAS FORMAS ELEMENTALES DEL DERECHO (EL PENSAMIENTO JURÍDICO DE EMILE DURKHEIM)
}

The elementary forms of Law (The legal thought of Emile Durkheim)

DOI: http://dx.doi.org/10.15304/dereito.28.2.5888

\section{BENJAMÍn RivaYA GARCÍA}

Profesor Titular de Filosofía del Derecho

Universidad de Oviedo

rivaya@uniovi.es

\section{Resumen}

La teoría del Derecho de Emile Durkheim resulta un clásico del pensamiento sociológico jurídico, imprescindible para comprender su objeto en el marco de la vida social. En este sentido, su comprensión organicista de la sociedad trae consigo una teoría medicalista del Derecho; la comprensión armonicista de la sociedad, una teoría funcionalista del Derecho; su comprensión positiva de la sociedad, una teoría optimista del Derecho.

Palabras clave: Durkheim; Teoría del Derecho; Sociología del Derecho; Antropología jurídica; Sociologismo.

\section{Abstract}

Emile Durkheim's theory of Law is a classic of legal sociological thought, essential to understand the Law in the framework of social life. So, his organicist doctrine of society implies a medical theory of Law, his harmonicist doctrine of society implies a functionalist theory of Law, his positive doctrine of society implies an optimistic theory of Law.

Keywords: Durkheim; Theory of Law; Legal Sociology; Legal Anthropology. Sociologism.

\section{SUMARIO}

1.- LA TEORÍA SOCIAL DE EMILE DURKHEIM.; 1.1.- Función, estructura y solidaridad social.; 1.2.- Algunas críticas a la teoría social de Durkheim.; 2.- LA TEORÍA JURÍDICA DE EMILE DURKHEIM.; 2.1.- El concepto de norma en Durkheim.; 2.2.- El concepto de Derecho en Durkheim.; 2.3.La teoría penal de Durkheim.; 2.4.- Otras ideas de Durkheim sobre el Derecho.; 2.5.- El fundamento del Derecho o el sentido de la vida social.; 3.- CONCLUSIÓN.; 4.- BIBLIOGRAFÍA.

\section{SUMMARY}

1.- THE SOCIAL THEORY OF EMILE DURKHEIM.; 1.1.- Function, structure and social solidarity.; 1.2.- Some criticism of Durkheim's social theory.; 2.- THE LEGAL THEORY OF EMILE DURKHEIM.; 2.1.- The concept of rule in Durkheim.; 2.2.- The concept of Law in Durkheim.; 2.3.- The penal theory of Durkheim.; 2.4.- Other ideas from Durkheim about Law.; 2.5.- The 
foundation of the Law or the meaning of social life.; 3.- Conclusion.; 4.Bibliography.

Es tanta la importancia que el pensamiento de Emile Durkheim ha tenido para las ciencias sociales, que resulta difícil circunscribirlo a una sola de ellas $^{1}$. De hecho, Durkheim no sólo ha pasado a la historia de las ideas por su impresionante contribución a la sociología, sino también a la filosofía, la pedagogía, la teoría de la religión y, lo que nos interesa especialmente, a la jurisprudencia y la etnología ${ }^{2}$. En el caso del fenómeno jurídico, su perspectiva tiene especial importancia, y no sólo porque le dedicara particulares estudios, sino porque la explicación que de él otorga se integra en una comprensión más amplia de la realidad social, a la vez que a veces -dicen- parece comprender ésta en clave jurídica, con lo que su sociología quedaría reducida a una sociología del Derecho ${ }^{3}$. Así todo, conviene exponer sucintamente la concepción social del francés, para luego examinar en concreto el lugar que el Derecho ocupa en su pensamiento total ${ }^{4}$.

\section{LA TEORÍA SOCIAL DE EMILE DURKHEIM}

\subsection{Función, estructura y solidaridad social}

En L'Education Morale, una obra póstuma en la que se recogieron algunos de los cursos de pedagogía que dictó Durkheim, al referirse a la fuente de la autoridad dijo lo que defendió en otros lugares, pero lo expresó de forma distinta a como lo hacía habitualmente; dijo que ese origen se hallaba en un superhombre, en un ser superior que pensaba, sentía y vivía de forma distinta a la manera en que los particulares seres humanos lo hacían. Páginas más adelante explicó que el respeto que ese superhombre merecía no era debido a la superioridad de su cuerpo sino

\footnotetext{
${ }^{1}$ En el seno de una familia judía, Emile Durkheim nace en Épinal, en 1858 . En 1882 se

${ }^{2}$ Por lo que a su concepción del Derecho se refiere, normalmente se suele decir que sus obras más importantes son De la División, Lecons de Sociologie y "Deux lois de I'évolution pénale"; por ejemplo R. Marra, Il diritto in Durkheim. Sensibilitá e riflessione nella produzione normativa, Edizioni Scientifiche Italiane, Napoli, 1986 (198 p.), p. 11. Para la antropología, la importancia de Durkheim se debe al estímulo que le ofreció en las páginas de L'Année sociologique, así como a sus estudios sobre el incesto, la magia o el matrimonio. Por lo demás, se considera que su obra etnológica fundamental fue Les formes élémentaires de la vie religieuse: vid. R. H. LOWIE, Historia de la etnología [1937] (trad. por P. Kirchhoff), FCE, México, 1981 (355 p.), p. 241 y 243.

${ }^{3}$ Como dice Lamo de Espinosa, ésta es "una interpretación habitual de Durkheim", pues si para él la sociología es un estudio de la solidaridad social, entonces "queda metódicamente reducida a sociología del Derecho, y especialmente de la sanción jurídica, como elemento externo y visible de la solidaridad"; en E. Lamo de Espinosa, "Social and Legal Order in Sociological Functionalism", Contemporary Crises 4, 1980, 44.

${ }^{4}$ Aunque Durkheim no fue un jurista ni recibió formación jurídica, el Derecho tiene en su obra gran presencia, hasta el punto de que "de su pensamiento se desprende una determinada concepción sociológica del Derecho"; vid. G. Robles, Crimen y castigo (Ensayo sobre Durkheim), Civitas, Madrid, 2001 (132 p.), p. 19-20. Esa presencia se debe, sin duda, a que para Durkheim el Derecho es "un hecho social privilegiado"; S. VILLENEUVE, "Durkheim. Reflexions sur la méthode et sur le droit", APD XIV, 1969, p. 244.
} 
de su alma ${ }^{5}$. Aunque así fuera, eso no impidió que en otras ocasiones se refiriera a los atributos orgánicos de semejante persona: el cerebro, las vísceras, los nervios. En concreto, manifestó que el cerebro del superhombre era el Estado ${ }^{6}$, con lo que se veía claro que lo que Durkheim hacía era tratar de comprender qué era la sociedad por medio de la analogía organísmica tan querida de algunos clásicos, pero quizás también utilizándola con mayor radicalidad. Que se trataba de una comparación lo reconoció él mismo cuando aclaró que si hablaba de solidaridad orgánica era por razón de esa analogía, por más que el símil no fuera perfecto ya que mientras las funciones biológicas eran fijas, las sociales en cambio eran elásticas ${ }^{7}$, o cuando criticó a los biólogos por hacer un uso incorrecto de la analogía, al pretender inducir las leyes sociológicas de las biológicas ${ }^{8}$. Sin embargo en otro lugar, al tratar del suicidio, vino a decir que el organicismo que defendía expresaba algo real y que no se reducía sólo a "metáforas y maneras de hablar" .

Pero comenzamos diciendo que el ser social, como el individual, se componía de cuerpo y alma, y que para Durkheim tenía más importancia la segunda que el primero. ¿Qué entendía Durkheim por alma social o colectiva? El conjunto de representaciones de la conciencia que, sin poder pertenecer a ningún individuo en particular, tenía existencia objetiva y se imponía sobre los miembros de un grupo. "Sin duda, las propiedades elementales de donde resulta el hecho social, están contenidas en germen en los espíritus particulares. Pero el hecho social no sale de éstos sino cuando aquéllas han sido transformadas por la asociación, puesto que solamente en este momento es cuando aparece" ${ }^{10}$. No extraña que redujera la analogía organísmica al solo espíritu, en el sentido de que la sociedad quedara identificada con la propia conciencia colectiva, de tal manera que aquélla era, sobre todo, "un conjunto de ideas y de sentimientos, de ciertas maneras de ver y sentir, cierta fisonomía intelectual y moral que es distintiva del grupo entero ${ }^{11}$.

En cualquier caso ya sabemos que para Durkheim la sociedad piensa, siente y quiere, aun de forma sui generis porque aunque no se identifique

\footnotetext{
${ }^{5}$ La educación moral [1925] (trad. por M.L. Navarro: L'Education morale), Buenos Aires, Losada, Buenos Aires, 1947 (264 p.), p. 65-66, 91 y 120.

${ }^{6}$ Lecciones de Sociología (Física de las costumbres y del Derecho) [1912] (trad. por D. Maldavsky: Lecons de sociologie: physique des moeurs et du droit), Schapire, Buenos Aires, 1974 (205 p.), p. 34.

7 La división del trabajo social [1893] (trad. por C.G. Posada: De la División du Travail Social), Akal, Madrid, 1995 (491 p.), p. 154 y 394.

${ }^{8}$ E. Durkheim, Educación como socialización, Sígueme, Salamanca, 1976 (274 p.), p. 52.

${ }^{9}$ El suicidio [1897] (trad. por ¿?: Le suicide: étude de sociologie), Akal, Madrid, 1995 (450 p.), p. 335.

10 Ibidem, p. 340.

${ }^{11}$ La educación moral, cit., p. 258. El historicismo y el romanticismo de Durkheim se hacen patentes. Ya en De la división dijo que "cada nación tiene su escuela de filosofía moral en relación con su carácter"; La división del trabajo social, cit., p. 466, y en $L$ 'Education vino a reconocer la existencia de "fuerzas colectivas y anónimas", fuerzas "que conducen a los pueblos"; La educación moral, cit., p. 257. ¿Se trataba, al final, de la reivindicación del carácter nacional francés?
} 
con lo que piensen, sientan o quieran los individuos, tampoco puede hacerlo al margen de éstos ${ }^{12}$. Pero en Les formes élémentaires de la vie religiense aún lo expresó de forma mucho más detallada y radical. Por una parte la sociedad siente emociones: puede llorar, entristecerse, sentirse amenazada y angustiada, encolerizarse, pero también amansarse, serenarse y recuperar la confianza. Además tiene intereses: "está interesada en que la cosecha sea abundante, en que la lluvia venga a tiempo y sin excesos, 0 en que los animales se reproduzcan normalmente ${ }^{\prime 13}$. Por otra parte, no sólo tiene una imagen de cada uno de nosotros que formamos parte de ella, sino que nos habla, a veces sugerente y a veces amenazante hasta la violencia, sometiéndonos y exigiéndonos sacrificios, creando ideales que compartir e imponiéndonos deberes. Valga por su crudeza el ejemplo del duelo que sigue al fallecimiento de un ser querido, y que no es, como habitualmente se cree, "la expresión espontánea de emociones individuales" sino, muy al contrario, "un deber impuesto por el grupo". Los miembros no tendrán conciencia del mecanismo, ni hay necesidad de que la tengan, y sentirán su turbación como auténtico dolor personal, incapaces de ver en él la actuación de poderosas fuerzas impersonales: "las emociones que despierta en el grupo la muerte de uno de sus miembros"14. En fin, la sociedad no deja de ser "una individualidad, con su fisonomía personal y su idiosincrasia" propias $^{15}$.

El ejemplo del duelo vale como manifestación de las relaciones que guarda la sociedad con los individuos, uno de los tópicos de la filosofía social de Durkheim y que le valió, por cierto, las críticas más agrias. Ya en De la División du Travail Social había dicho que el grupo no sólo regentaba la vida de sus miembros, pues cumplía otras funciones ${ }^{16}$, con lo que se evidenciaba que también lo hacía, regentar la vida de los miembros, quiero decir. Después explicará con mayor claridad cómo la sociedad llevaba a cabo el dominio. Para empezar, porque era la sociedad la que creaba al ser humano: "el hombre no es hombre más que porque vive en sociedad"17. Así, resultaba que había una "dualidad constitucional" en la naturaleza humana ${ }^{18}$, que en todo individuo se podía distinguir, aunque no fuera más que a efectos teóricos, entre una parte individual, personal, íntima, y otra impersonal, social, colectiva, que se le imponía quisiéralo o no ${ }^{19}$. Las citas podrían multiplicarse, pero baste con una que apunta a todo ese instrumental social que hace que el hombre sea lo que es:

\footnotetext{
12 Por ejemplo, Educación como socialización, cit., p. 74.

${ }^{13}$ Las formas elementales de la vida religiosa [1912], Alianza, Madrid, 1993 (698 p.), p. 552.

14 Ibidem, p. 623-629.

15 Ibidem, p. 692.

${ }^{16}$ La división del trabajo social, cit., p. 31.

${ }^{17}$ Educación y sociología [1922], Altaya, Barcelona, 1999 (188 p.), p. 57; Lecciones de Sociología, cit., p. 61.

18 Durkheim, E., La science sociale et l'action, Presses Universitaires de France, Paris, 1970 (334 p.), p. 315.

${ }^{19}$ Educación como socialización, cit., p. 141.
} 
"Hablamos una lengua que no hemos forjado nosotros; nos servimos de instrumentos que no hemos inventado; invocamos derechos que no hemos instituido; a cada generación se le transmite todo un tesoro de conocimientos que ella no ha amasado, y así sucesivamente. Estos beneficios variados de la civilización se los debemos a la sociedad, y aunque, por lo general, ignoramos de dónde proceden, al menos sabemos que no son obra nuestra. Pero son precisamente ellos los que otorgan al hombre su fisonomía propia entre todos los demás seres; pues el hombre sólo es hombre por el hecho de estar civilizado"20. El atomismo social, por tanto, la doctrina individualista que pretendía que el hombre era un todo independiente, que se bastaba a sí mismo y por sí mismo vivía, constituía un tremendo error, y más cuando pretendía que era la simple suma de esos seres individuales la que constituía la sociedad, sin darse cuenta de que "un todo no es idéntico a la suma de sus partes"21.

El reconocimiento de una conciencia social que necesariamente pasaba a formar parte de la conciencia de los individuos, que las invadía ${ }^{22}$, traía consigo unas consecuencias de singular importancia: por una parte la afirmación del carácter moral de la sociedad y, por otra, la de la armonía social. En cuanto a lo primero, lo repitió incansable a lo largo de toda su obra. Ya en La división comparó la moral con el pan, en el sentido de que aquélla era tan importante para la sociedad como el pan para los individuos, y luego, en la misma obra, aseguró que decir sociedad era tanto como decir "sociedad moral"23. Expresa o tácita, la misma idea fue apareciendo en lo que iba publicando. Por fijarse en el final del periplo, en una obra póstuma, sus Lecons de Sociologie, afirmó que el orden era una "obra moral", con lo que venía a significar lo mismo ${ }^{24}$, que la sociedad, cualquier sociedad, era un producto moral, o que la sociedad era, sin que pudiera ser de otra forma, una sociedad moral. Así, con más razón incluso que se afirma de los concretos seres humanos que poseen personalidad moral, la sociedad también la posee o, mejor, la misma sociedad es la personalidad moral ${ }^{25}$. En cuanto al otro asunto apuntado, el de su armonicismo, Durkheim siempre afirmó que para que pudiera hablarse de sociedad era necesario que al menos en cierto grado reinara la armonía, a la que llamó también cooperación, integración y, sobre todo, solidaridad. "Esta solidaridad no consiste sólo en una unión general e indeterminada del individuo al grupo, sino que hace también que sea armónico el detalle de los movimientos". En fin, sin coordinación de las funciones era imposible la existencia social ${ }^{26}$. De hecho, la distinción durkheimiana entre solidaridad mecánica y orgánica se refiere a las distintas maneras que hay de satisfacer esta necesidad de integración. En el caso de la primera, que se produce por "causas mecánicas" y "fuerzas impulsivas", el

\footnotetext{
${ }^{20}$ Las formas elementales de la vida religiosa, cit., p. 350.

${ }^{21}$ La educación moral, cit., p. 240 y 247; Lecciones de Sociología, cit., p. 64.

${ }^{22}$ El suicidio, cit., p. 419.

${ }^{23}$ La división del trabajo social, cit., p. 60 y 269.

${ }^{24}$ Lecciones de Sociología, cit., p. 16.

${ }^{25}$ Educación y sociología [1922], Altaya, Barcelona, 1999 (188 p.), p. 60.

${ }^{26}$ La división del trabajo social, cit., p. 124 y 454-455.
} 
acoplamiento es más precario, mientras que una cooperación más compleja, junto con la división del trabajo, traen consigo una mayor perfección de la solidaridad, que denomina orgánica ${ }^{27}$. Pero aun cuando la sociedad fuera sobre todo cooperación ${ }^{28}$, tampoco puede pretenderse que Durkheim desconociera la existencia de conflictos y luchas. Como se verá más adelante, a su juicio el crimen era normal, y no por eso dejaba de ser un quebrantamiento del orden, una negación de la solidaridad ${ }^{29}$. Así todo, una de las críticas más habituales le acusará por desconocer el funcionamiento real, conflictivo, de las sociedades, desconocimiento que decían- tendría una clara lectura política.

El enfrentamiento de Durkheim con el movimiento obrero, sobre todo con las corrientes marxistas, resulta patente. La lucha de clases era -a su juicio- una patología ${ }^{30}$. Hay que darse cuenta de la importancia que semejante afirmación tiene para quien forma parte de una estirpe organicista y medicalista, para quien concibe la salud como ideal, como estado que debe ser ("un punto de referencia precioso para orientar la conducta") y, por tanto, entiende la enfermedad como algo indeseable, al menos más allá de ciertos límites ("una cosa mala que debe ser evitada"). El criterio de medición, entonces, se halla en la facilidad o la dificultad para la supervivencia ${ }^{31}$. Tanto en lo social como en lo individual, por tanto, la salud se traduce en armonía y felicidad ${ }^{32}$; la enfermedad, en perturbación y sufrimiento ${ }^{33}$. Repárese, porque tiene importancia, en las enfermedades sociales que apuntó Durkheim: la depresión, la astenia y la melancolía colectivas ${ }^{34}$; todas ellas enfermedades del espíritu.

Así, resultaba que la teoría social de Durkheim se centraba más en los aspectos morales, mentales o ideológicos que en los fácticos, los físicos o materiales. Del marxismo no sólo criticó la lucha de clases sino también el principio del determinismo económico ${ }^{35}$. Lo que realmente le preocupaba del ser social era su espíritu y, en perspectiva científica, la cuestión de cómo encarar el estudio de éste, para lo que puso las bases de una nueva ciencia al exponer cuáles debían ser las reglas del método sociológico. Desde bien pronto afirmó que la psicología no era un conocimiento apropiado para estudiar ese objeto, pues si bien podría dar cuenta de los estados de la conciencia individual, producidos éstos por la vida mental de los hombres, difícilmente podría pretender lo mismo cuando la conciencia

\footnotetext{
27 Ibidem, p. 321 y 325.

${ }^{28}$ Las reglas del método sociológico [1895], Morata, Madrid, 1984 (159 p.), 48.

29 Ibidem, p. 14; La división del trabajo social, cit., p. 416.

${ }^{30}$ Por ejemplo, El suicidio, cit., p. 271.

${ }^{31}$ Las reglas del método sociológico, cit., p. 70-71 y 78; La división del trabajo social,cit., p. 401-403.

${ }^{32}$ La división del trabajo social, cit., p. 276 y 290.

33 Ibidem, p. 441

${ }^{34}$ El suicidio, cit., p. 220-221 y 214.

35 En efecto, Durkheim critica duramente el principio del determinismo económico, que no puede pretender convertirse en la ley de la historia de la humanidad, asegura; vid. E. DURKHEIM, recensión de "Antonio Labriola. Essais sur la conception materialiste de I'histoire. Paris. Giard et Brière, 348 p.", Revue Philosophique XLIV, 1897 (p. 645-651).
} 
era colectiva ${ }^{36}$. El espíritu social sólo podría ser estudiado por una ciencia distinta que no equiparase aquél al de los particulares individuos, y esta ciencia era la sociología. En pocas palabras, la psicología, que se dedicaba al estudio de las representaciones individuales, era "la ciencia del individuo" ${ }^{37}$, mientras que la sociología, que se ocupaba con las representaciones colectivas, era la de la sociedad. Entre una y otra no cabía confusión, por tanto, pero se debe advertir que la sociología durkheimiana no dejaba de ser otra psicología, no de las vivencias mentales de los hombres concretos, sino de las del superhombre social. Que yo sepa, lo dijo al menos en dos ocasiones. En Le Suicide negó que la vida social no tuviera nada de psíquica. "Es evidente, al contrario, que está hecha esencialmente de representaciones. Sólo que las representaciones colectivas son de una naturaleza completamente distinta de las del individuo. No vemos ningún inconveniente en que se diga de la sociología que es una psicología, si se tiene cuidado de añadir que la psicología social tiene sus leyes propias, que no son las de psicología individual" ${ }^{38}$. Después, de forma aún más expresa, sin ambages, afirmó que la sociología no era otra cosa que "psicología colectiva" ${ }^{39}$. Bastará, por tanto, con estudiar la psique de un pueblo, su espíritu, su moral, para poder decir que se conoce ${ }^{40}$.

En cuanto al procedimiento que propuso Durkheim para estudiar la sociedad y los fenómenos sociales, fue una mezcla de estructuralismo y funcionalismo. Estructuralismo, porque la conciencia colectiva no dejaba de ser una serie de estructuras, un conjunto de representaciones de modelos a los que se sometía la realidad. Al fin y al cabo, fue el propio Durkheim quien dijo que por estructura entendía "la manera de ser" de las cosas, lo que también traía consigo ciertas formas de obrar ${ }^{41}$. Aun sin decir que se refería a esas estructuras, una definición que marcaría el futuro desarrollo del estructuralismo apareció más explícita en Les formes élémentaires: "los marcos que se aplican a la totalidad de los seres y que permiten pensarlos. Esos marcos no los crea artificialmente, sino que los encuentra en ella, limitándose a hacerlos conscientes" ${ }^{42}$. Funcionalismo, porque al clásico le preocupaba esencialmente la función que cumplían los hechos sociales, si bien advertía contra las explicaciones funcionalistas demasiado genéricas ${ }^{43}$, al igual que contra la pretensión de que todo lo que existe tenga una función ("un hecho puede existir sin servir para nada") y sólo una función (un órgano puede servir "para fines

\footnotetext{
36 Por ejemplo, Las reglas del método sociológico, cit., p. 23.

37 Educación y sociología, cit., p. 112.

38 El suicidio, cit., p. 341-342.

39 Educación como socialización, cit., p. 81, n. Esa psicología social, la sociología, no sólo estudiaría la conciencia social sino también el "subconsciente" colectivo: La educación moral, cit., p. 78.

40 La educación moral, cit., p. 88.

41 La división del trabajo social, cit., p. 394.

42 Las formas elementales de la vida religiosa, cit., p. 691.

43 La división del trabajo social, cit., p. 271.
} 
diferentes" $)^{44}$. Realmente en un organismo, también en el social, sólo se puede decir que un miembro o un órgano o una institución desempeñan una función si y sólo si contribuye al "mantenimiento de la vida general", con lo que el miembro, el órgano o la institución pueden funcionar mejor o peor, y en este último caso lo que queda es "cambiar el orden establecido" ${ }^{45}$. Claro que con el paso del tiempo Durkheim fue limitando esa posibilidad, llegando a afirmar que cada sociedad tiene la moral que le corresponde, como cada organismo vivo tiene el sistema nervioso que le es propio ${ }^{46}$. Se trataba, por lo menos, de la presunción de que lo establecido está bien establecido, o al menos la constatación de la necesidad de cierta estabilidad, de que el continuo cambio no es deseable ${ }^{47}$. En otros términos, Durkheim pensaba que el mantenimiento de la vida de la sociedad ( $y$ en último término de la especie humana) era un objetivo moral o, quizás mejor, el objetivo moral por excelencia. Al fin y al cabo, era la propia naturaleza la que así lo establecía: "el reino social no es menos natural que el reino orgánico", es naturaleza ${ }^{48}$. Evidentemente, los hombres no habían constituido las sociedades "para satisfacer necesidades especulativas" ${ }^{\prime 4}$, sino para vivir. Pero para lograrlo sólo se podía hacer por medio de una forma de vida determinada. Las formas de vida, claro, podrían ser más o menos adecuadas o, en términos morales, más o menos justas o injustas. Ante una lamentable, lo mejor sería derrocarla a cambio de otra mejor. Ahora bien, lo que no parecía razonable sería una continua subversión que convirtiera la vida en una constante provisionalidad, lo que hacía que estableciera una presunción de corrección en favor de la forma de vida impuesta de facto.

\subsection{Algunas críticas a la teoría de la sociedad de Durkheim}

Dado que Durkheim ha sido uno de los padres de la sociología y, a la vez, inaugura una tendencia fundamental en la ciencia social, las críticas que se le han hecho han sido tantas y tan variadas que resulta difícil sistematizarlas. Algunas de ellas aparecerán más adelante, pero quizás ahora podría intentarse una clasificación que distinguiera dos tipos de censuras, según que se dirijan contra los principios del método científico por él apuntado y, por consiguiente, contra su concepción social general, o contra la opción política que -se dice- aparece tras sus ideas.

\footnotetext{
${ }^{44}$ Las reglas del método sociológico, cit., p. 107.

${ }^{45}$ La división del trabajo social, cit., p. 416 y 439-441.

${ }^{46}$ La educación moral, cit., p. 88.

47 En la misma obra vino a fundamentar esa presunción cuando se refirió a la estructura doméstica, profesional y cívica. Lo que no podía ser era "buscar perpetuamente su forma" $y$, por tanto, era "necesario que las normas que determinan lo que deben ser esas relaciones queden establecidas y que los individuos se sometan a ellas"; La educación moral, cit., p. 44.

${ }^{48}$ La división del trabajo social, cit., p. 412; Las formas elementales de la vida religiosa, cit., p. 54.

${ }^{49}$ Las formas elementales de la vida religiosa, cit., p. 674.
} 
Por lo que respecta a sus criterios metodológicos, ocurre que no todos los entienden de la misma forma, con lo que, a veces, las críticas parecen referirse a doctrinas distintas. Así, desde una perspectiva materialista se critica el espiritualismo, el idealismo, el mentalismo y el romanticismo de Durkheim, interesado sólo en afirmar la "prioridad causal de la ideología" sobre los otros factores sociales y la presunción "de que cada país tenía un alma que le mantenía aparte, como una "especie" social separada a través de todas las vicisitudes de su experiencia histórica" ${ }^{\prime 50}$. Pero no hay que ser materialista para criticar su manera de concebir la ciencia, pues sin serlo ya hubo quien dijo que era, precisamente, "acientífica"51.

Por lo que respecta a su opción política, probablemente sea cierto que a Durkheim no se le puede comprender al margen del contexto en el que elaboró su obra, "que es el de las predicciones marxistas de la inminente explosión del sistema capitalista", y de la función que desempeñó, la de amortiguar las difíciles relaciones entre las ciencias sociales y los conflictos revolucionarios de la época ${ }^{52}$. Tras lo obvio, sin embargo, se ocultaría la opción política que tomó Durkheim, que precisamente se explicaría "por su posición de clase". No es extraño que el marxismo ortodoxo viera en Durkheim un aliado del reformismo burgués que se dedica a repetir los slogans conservadores de la paz, la armonía y la solidaridad social ${ }^{53}$. Desde una perspectiva contraria, en cambio, el pensamiento de Durkheim es peligroso precisamente porque hipostasia la sociedad, bajo la que puede sucumbir el individuo ${ }^{54}$.

\section{LA TEORÍA JURÍDICA DE EMILE DURKHEIM \\ 2.1. El concepto de norma en Durkheim}

De entre el instrumental de conceptos que Durkheim perfiló, y del que se sirvió en sus investigaciones, destaca el concepto de norma, al que atribuyó una importancia que algunos han considerado excesiva, aunque desde el punto de vista de la teoría del Derecho resulta estimulante. Ya al principio de su primera gran obra dijo que la regla no era "sólo una manera de obrar habitual", sino, sobre todo, "una manera de obrar obligatoria, es decir, sustraída, en cierta medida, al libre arbitrio individual" ${ }^{\prime 55}$. Luego, en un lenguaje más poético, definió las normas como moldes en los "que tenemos que fundir nuestras acciones"56. Por fin, dijo

\footnotetext{
50 M. HARRIS, El desarrollo de la teoría antropológica. Una historia de las teorías de la cultura [1968] (trad. por R. Valdés), siglo veintiuno, Madrid, 1987 (690 p.), p. 402-417.

51 E. EVANS-PRITCHARD, Historia del pensamiento antropológico [1980] (trad. por I. Vericat), Cátedra, Madrid, 1987 (265 p.), p. 216.

52 M. HARRIS, El desarrollo de la teoría antropológica. Una historia de las teorías de la cultura, p. 404.

${ }^{53}$ E. OSIPOVA, "La sociología de Emile Durkheim" [1979] (trad. del ruso por I. Pozo), en VARIOS, Historia de la sociología del siglo XIX-comienzos del XX, Editorial Progreso, Moscú, 1989 (p. 207-258).

${ }^{54}$ Así lo advierte el gran filósofo del Derecho español, Luis Recaséns Siches, en su "Balance sobre Durkheim", Revista mexicana de Sociología 21, 3, 1959, p. 875-891.

${ }^{55}$ La división del trabajo social, cit., p. 5.

${ }^{56}$ Las reglas de método sociológico, cit., p. 54.
} 
que eran los "hechos morales y jurídicos" 57 . Por lo demás, las normas eran una clase de hechos sociales, esto es, de "formas de obrar, pensar y sentir, exteriores al individuo" y que "están dotados de un poder de coacción en virtud del cual se les impone", tales como las creencias religiosas, los preceptos morales, los sistemas financieros o las normas jurídicas" ${ }^{\prime 58}$.

Así las cosas, parece conveniente pararse en los elementos de las normas, es decir, en el dato de que sean formas de obrar obligatorias, exteriores y coactivas.

Que las normas son formas de obrar significa que son modelos de conducta 0 , si se quiere, conductas establecidas, más o menos fijadas, según los casos, que hay que seguir o, en otros términos, a las que se hay que someter. Por supuesto, sólo en un sentido excesivamente amplio podría decirse que las formas de pensar y sentir también son normas. La cuestión de la obligatoriedad (pues no sólo se trata de formas de obrar sino de formas obligatorias de obrar) conecta con las demás que veremos y se iluminará al examinarlas pero, en cualquier caso, sirve para aclarar una distinción fundamental, la de norma y hábito. Si por hábito entendemos repetición, entonces el hábito también es una forma de obrar, con lo que cumpliría el primer requisito para poder denominarlo norma. Sin embargo resulta evidente que el hábito por sí mismo no tiene ese carácter normativo, es decir, que se distingue de la norma. La diferencia se halla en que el sometimiento a las normas es debido a su "carácter obligatorio, al prestigio especial de que están investidas", mientras que quien se somete al hábito lo que hace es "repetir automáticamente lo que los demás han hecho". La diferencia tiene fundamental importancia porque quien trate de analizar la vida social a la luz de los conceptos de hábito, repetición, imitación y otros semejantes, será incapaz de comprender aquélla ${ }^{59}$. El comportamiento que más se repite, el instintivo, carece de normatividad. De forma expresa y tajante: "Un instinto no es una regla"60. Eso no significa, sin embargo, que entre el hábito y la norma no pueda existir continuidad; en ocasiones el hábito acaba convirtiéndose en norma, adquiriendo fuerza obligatoria: cuando ciertas conductas se repiten con mucha frecuencia es posible que se transformen en costumbres y después éstas, "a medida que toman fuerza, transformanse en reglas de conducta"61. Evidentemente, no se trata de que el hábito y la norma se confundan sino, lo que es muy distinto, de que aquél pueda convertirse en ésta; de que un comportamiento habitual que primero se tuvo por indiferente pase a ser debido. También es verdad que al final de su evolución Durkheim vino a reconocer que, "casi

\footnotetext{
${ }^{57}$ Lecciones de Sociología, cit., p. 8.

${ }^{58}$ Las reglas del método sociológico, cit., p. 35.

${ }^{59}$ El suicidio, cit., p. 111-114 y 129.

${ }^{60}$ Las formas elementales de la vida religiosa, cit., p. 579.

${ }^{61}$ La división del trabajo social, cit., p. 430. De hecho, para Durkheim, lo normal es que la costumbre sea la base del Derecho; cuando esto no ocurre estamos ante un caso raro, patológico; vid. R. A. JONES, Emile Durkheim. An introduction to four major works, Sage Publicationes, Beverly Hills, 1987 (165 p.), p. 29.
} 
inevitablemente", el hábito de una comunidad era normativo, pero a renglón seguido añadió que por sí solo no bastaba para que hubiera norma, pues no era obligatorio ${ }^{62}$. Por lo demás, que la norma sea una forma de obrar no significa que siempre y en todo caso se obre como la norma indica, pues siempre hay infracciones ${ }^{63}$. Como luego veremos, lo que ocurre es que las excepciones a la regla, aunque siempre las haya, no pueden ser ilimitadas.

El hecho de que sean exteriores al individuo significa que no son creadas por él, sino que le vienen impuestas desde afuera, es decir, que "actúan sobre nosotros desde el exterior" ${ }^{\prime 64}$. En otros términos, se nos imponen. En este sentido no extraña que hayan sido vistas como un fastidio que constriñe a los individuos, por muy necesarias que sean. Bentham, por ejemplo, entiende que son nada menos que "una especie de patología"65. En efecto, las normas exigen control del propio cuerpo, de los instintos, sometimiento a una disciplina que exige sacrificios ${ }^{66}$, y no extraña que haya quien las vulnere con gusto. Pero también es cierto que se hallan revestidas de prestigio, de autoridad, y que, aunque sean en gran medida irreflexivas, provocan respeto y aceptación voluntaria ${ }^{67}$. Si esto es así, entonces lo que en cierta ocasión dijo el propio Durkheim, que "quien dice obligación dice coacción" ${ }^{\prime 68}$, o bien se trató de un maximalismo o bien debe ser completado en el sentido de que quien dice obligación dice coacción, pero también respeto y asunción.

En este punto hay que referirse a la cuestión del origen de las normas, la del sujeto que las crea, quiero decir, dado que, como veremos más adelante, Durkheim no creía que el contenido de las pautas de conducta fuera natural. Además, aunque tenga un carácter más general, el tema afecta muy especialmente a las normas jurídicas, toda vez que la teoría que siempre rebatió (aunque con desigual intensidad) fue la del legislador omnipotente. Desde luego, ya quedó demostrado que las normas no son creadas por los particulares individuos puesto que son, como vimos, exteriores a ellos. Resta por saber, por tanto, quién las crea. Al tratar de la desaprobación que generaba el suicidio en sus días, dijo que ya no tenía tanta intensidad como antaño y que el legislador, por tanto, no podría castigarlo como antes. "No depende del legislador el que un hecho se nos aparezca o no como moralmente odioso", sentenció ${ }^{9}$. Más tarde se reiría de esa creencia que atribuía a una persona o a un órgano la posibilidad de "crear de la nada una institución", por su simple voluntad, como si un sistema social pudiera erigirse o modificarse significativamente porque alguien así lo quisiera. Al contrario, la norma es una creación colectiva,

\footnotetext{
${ }^{62}$ La educación moral, cit., p. 34-35.

${ }^{63}$ La división del trabajo social, cit., p. 443.

${ }^{64}$ Las reglas del método sociológico, cit., p. 28.

${ }^{65}$ La educación moral, cit., p. 42.

${ }^{66}$ Educación como socialización, cit., p. 41.

67 Las reglas del método sociológico, cit., p. 28; El suicidio, cit., p. 148; La educación moral, cit., p. 86-89, 118 y 147-148.

${ }^{68}$ La división del trabajo social, cit., p. 60.

${ }^{69}$ El suicidio, cit., p. 416.
} 
una "obra de todos", y por eso tiene tras de sí la autoridad social" Evidentemente, si esta doctrina era aplicable a todos los hechos sociales, también correspondía a las normas jurídicas que, como las demás, eran la construcción del grupo y funcionaban gracias a su autoridad ${ }^{71}$.

Por fin, el carácter coactivo, que se tiene por el característico del concepto de norma en Durkheim, presenta -a mi juicio- mayores problemas, toda vez que no queda claro, como ya vimos, cuál es el papel que le corresponde a la coacción en la configuración de la norma. ¿Se trataba del elemento fundamental, de un elemento fundamental o de la consecuencia posible del incumplimiento de la norma? Esto es, ¿formaba o no formaba parte del concepto de norma? La opinión más extendida suele afirmar que la sanción resulta ser el eje de la norma durkheimiana. Sin duda es cierto que en Les régles afirmó que para él la coacción era lo característico de todo hecho social, pero también que era el signo exterior que enseñaba que había una norma ${ }^{72}$. Poco después, en un artículo de 1.898 advirtió que tenía que rectificar una interpretación inexacta de su pensamiento: "Cuando dijimos, al hablar de la obligación o de la constricción, que es ésa la característica de los hechos sociales no pensamos ni mucho menos en dar así una explicación sumaria de estos últimos, sino que quisimos indicar solamente una cómoda señal por la que el sociólogo puede reconocer los hechos que entran dentro de su ciencia"73. En algunas de sus obras póstumas insistiría sobre este punto, cuando aseguró que tan verdad era que no había regla sin sanción como que las sanciones se unían a las reglas ${ }^{74}$, con lo que parecía dar a entender que no formaban parte de ellas, que eran un añadido, seguro que empíricamente necesario, pero no conceptualmente exigido. En las Lecons de sociologie volvió a decir que se trataba del "signo exterior", de la "prueba sensible" de que había una norma, pero que no se identificaba con ésta ${ }^{75}$. Si la cuestión tiene alguna importancia no se debe tanto a las imprecisiones de Durkheim cuanto a las interpretaciones mayoritarias que lo presentan como un imperativista defensor a todo trance de la fuerza, reduciendo así su teoría de la sociedad a la imposición descarnada de ésta. Desde luego, es un aspecto de la vida social, pero se olvida del otro más importante aún, la necesidad de que las reglas se respeten por su misma dignidad y no por miedo al castigo, pues si así fuese se distorsionaría la vida social misma $^{76}$.

\footnotetext{
${ }^{70}$ Las formas elementales de la vida religiosa, cit., p. 53, 68 y 576.

${ }^{71}$ Lecciones de Sociología, cit., p. 12.

72 Las reglas del método sociológico, cit., p. 64 y 130.

73 Educación como socialización, cit., p. 74.

${ }^{74}$ La educación moral, cit., p. 150 y 153.

75 Lecciones de Sociología, cit., p. 72. También es cierto que en la misma obra afirmó que la sanción era el "elemento esencial de toda regla", pero lo explicó de la siguiente forma: el robo se castigaba porque estaba prohibido, esto es, que la "sanción no se relaciona, pues, con la naturaleza intrínseca del acto, puesto que si la sanción puede desaparecer, el acto permanece como tal. La misma depende por completo de la relación que tiene dicho acto con una regla que lo permite o prohíbe"; Lecciones de Sociología, cit., p. 8.

${ }^{76}$ La educación moral, cit., p. 37.
} 
Por último, al margen ya de los elementos estructurales de la norma, hay que referirse a la función que Durkheim le asignó, pues sabemos que nunca desdeñó la perspectiva funcionalista a la hora de estudiar las instituciones sociales. Las normas tenían por fin posibilitar la vida social, lo que explicaba la reacción que seguía al incumplimiento de una de ellas, precisamente para evitar la desintegración de la sociedad ${ }^{77}$. Así, no extraña el carácter valioso que Durkheim asigna a las normas; tanto que normatividad significa libertad ${ }^{78}$, que quien las cumple muestra que goza de una "sana constitución moral"79, que permiten que el hombre sea como debe, esto es, conforme a su naturaleza ${ }^{80}$; en fin, que son nada menos que la condición necesaria para la felicidad y la salud ${ }^{81}$. Las normas, por tanto, cumplen una importante función moderadora que, cuando por lo que sea no se produce, trae consigo que la propia sociedad se resienta y sufra. Se trata del mal de la anomia, con sus indeseables consecuencias de desintegración, criminalidad, suicido, entre otras ${ }^{82}$.

\subsection{El concepto de Derecho en Durkheim}

Vista la doctrina que Durkheim elaboró sobre lo que fuera la normatividad, resulta evidente que el Derecho aparece como un capítulo concreto dentro de esa teoría más general. De hecho, los postulados básicos de su pensamiento al respecto pueden resultar obvios, aunque a veces se olvidan: el Derecho expresa "un estado determinado del alma colectiva"83, por lo que sólo hay Derecho si hay sociedad ${ }^{84}$. El estudio de aquél, para Durkheim uno de los paradigmas del hecho social, requiere el conocimiento de ésta. Cuando se refirió a "los hechos morales y jurídicos", dijo que se podía expresar "más brevemente" diciendo sólo "los hechos morales" 85 , con lo que reconocía que las normas jurídicas eran, en un sentido amplio, normas morales o, lo que es lo mismo, que las normas de Derecho se integraban dentro de la normatividad social, que eran normas sociales, lo que no quiere decir que no tuvieran rasgos peculiares que las distinguían de otras. Que yo sepa no utilizó la expresión que luego popularizarían otros de vida social cristalizada, pero sí utilizó esas palabras para referirse a la misma idea: "La vida social que se ha como cristalizado y fijado sobre soportes materiales, se encuentra pues, por esto mismo, exteriorizada, y es desde fuera desde donde obra sobre nosotros", dijo, y luego aclaró que se refería, por ejemplo, a los dogmas religiosos o a las normas jurídicas ${ }^{86}$. En otra ocasión señaló que en las sociedades "los sentimientos colectivos se cristalizan", y así surgen

\footnotetext{
77 La división del trabajo social, cit., p. 466.

78 Ibidem, p. 453.

79 El suicidio, cit., p. 266.

80 La educación moral, cit. p. 56.

81 Ibidem, p. 121.

82 La división del trabajo social, cit., p. 433 ss.; El suicidio, cit., p. 255 ss.

${ }^{83}$ Las reglas del método sociológico, cit., p. 38.

84 La división del trabajo social, cit., p. 324.

85 Lecciones de Sociología, cit., p. 8.

${ }^{86}$ El suicidio, cit., p. 344.
} 
proverbios populares, apotegmas, máximas morales y jurídicas ${ }^{87}$. Las normas jurídicas, por tanto, presentaban la rigidez de lo que de alguna forma se había fijado o cristalizado, es decir, que se caracterizaban por una cierta permanencia, porque aunque se aplicaran muchas veces constituían "un objeto fijo" que cualquier observador podía captar objetivamente. "Una regla de derecho es lo que es y no hay dos maneras distintas de percibirla", sentenció ${ }^{88}$. Pero también se habían fijado verbalmente los refranes, por ejemplo, y evidentemente no eran Derecho. ¿Qué era lo propio del fenómeno jurídico? En De la división, donde dedicó una sección a plantearse esta cuestión, dio a entender que su fijeza era mayor que la que se producía en otros casos. Vinculó el orden jurídico con lo permanente, lo definido, lo estable y preciso, lo consolidado, y así lo contrapuso a la costumbre, a la moralidad, que también sería una reglamentación social pero difusa. Expresamente dijo que la norma jurídica era una "regla de conducta sancionada", pero a renglón seguido añadió que las normas del Derecho penal estaban organizadas, esto es, que eran aplicadas por un "órgano definido". Aunque se calló ese carácter cuando se refirió al Derecho restitutorio (el civil, el mercantil, el procesal, el administrativo y el constitucional), era evidente que también le correspondía ${ }^{89}$. Así, el Derecho resultaba ser una forma de normatividad social, si bien se particularizaba por ser más concreto el contenido de sus preceptos y por tener a su servicio una organización específica, lo que no ocurría con las otras normas sociales ${ }^{90}$.

En otra ocasión Durkheim apuntó que el Derecho era necesario, que satisfacía necesidades vitales de la sociedad y que lo había, por tanto, desde antes de que existiera una ciencia social dispuesto a estudiarlo ${ }^{91}$. Parecía optar por un concepto amplio de Derecho, según el cual se trataba de una organización que todas las sociedades tendrían. Ahora bien, si para que pudiera hablarse de ordenamiento jurídico era necesario que existiesen tribunales, ¿acaso en todas las sociedades funcionaban tales órganos? El concepto que Durkheim dio de éstos (de nuevo al referirse al Derecho penal) era de tal amplitud que probablemente así fuera: "Sea cual fuere la manera como se componga, comprenda a todo el pueblo o sólo a algunos elegidos, siga o no un procedimiento regular en la instrucción del asunto como en la aplicación de la pena, sólo por el hecho de que la infracción, en lugar de ser juzgada por cada uno se someta a la apreciación de un cuerpo constituido, y que la reacción colectiva tenga por intermediario un órgano definido, deja de ser difusa: es organizada. La

\footnotetext{
${ }^{87}$ La educación moral, cit., p. 228.

88 Las reglas del método sociológico, cit., p. 66.

89 La división del trabajo social, cit., p. 75-81.

90 En palabras de Cotterrell explicando las de Durkheim, en el caso del Derecho, "la sociedad juzga, pero de manera organizada. Así, el Derecho requiere algunos medios institucionalizados para declarar o afirmar públicamente normas"; R. COTTERRELL, Emile Durkheim. Law in a Moral Domain, Stanford University Press, Stanford, California, 1999 (276 p.), p. 61.

${ }^{91}$ Las reglas del método sociológico, cit., 45.
} 
organización podrá ser más completa, pero existe desde ese momento"92. Como en otras teorías realistas, entonces, lo que fuera el Derecho dependía de que hubiera tribunales ${ }^{93}$, con lo que se planteaban los problemas propios de éstas, pero además el concepto de tribunal que manejaba podía parecer excesivamente amplio.

En cuanto a las diversas clasificaciones del Derecho que Durkheim propuso, clasificaciones que también forman parte de su concepto de lo jurídico, hay que comenzar diciendo que, por considerarla empírica y aproximada, repudió la que era tradicional entre los juristas, la que distinguía entre un Derecho público y otro privado. En tanto que las normas jurídicas siempre regulaban conductas de individuos, resultaba que todo Derecho era privado y, a la vez, y fundamentalmente, todo era público, en el sentido de que nada en él era ajeno a la sociedad, de la que era una función: "todo el Derecho es público porque todo el Derecho es social. Todas las funciones de la sociedad son sociales, como todas las funciones del organismo son orgánicas". Parecía que Durkheim se sentía incómodo con los conceptos de los juristas, claros sólo a primera vista y cómodos para la práctica, pero nada más ${ }^{94}$. La clasificación durkheimiana más conocida, sugestiva pero "quizás un tanto simplista"95, es la que distingue entre un Derecho represivo y otro restitutivo, pero no es la única pues, relacionadas con la anterior, contrapuso el Derecho inconsciente al consciente, el estatutario al contractual, el arcaico al reciente y el religioso al humano. En el fondo se trataba de una misma clasificación, si bien utilizaba criterios diversos para presentarla, esto es, el Derecho represivo sería el Derecho inconsciente, estatutario, arcaico y religioso, mientras que el restitutivo sería consciente, contractual, reciente y humano. Atendiendo al tipo de solidaridad al que servía y a la sanción que utilizaba, el Derecho podría ser represivo o restitutivo. Atendiendo a su expresión, consuetudinario o legislativo, inconsciente o consciente. Atendiendo al contenido de la normativa, estatutario o contractual. Atendiendo al período histórico en que se producía, arcaico o reciente. Atendiendo a su fundamento, religioso o humano ${ }^{96}$.

Por otra parte, el carácter organicista de la filosofía social durkheimiana exige plantearse lo que resulta obvio para otras muchas teorías orgánicas de la sociedad, esto es, si no se trataba de una nueva teoría médica del Derecho. No es extraño que quien concibe la sociedad como un hombre en

\footnotetext{
92 La división del trabajo social, cit., p. 113.

93 Esa dependencia del concepto de Derecho de la organización de la sanción traía consigo, según Gurvitch, que del pensamiento de Durkheim quedara excluido "el derecho espontáneo, dinámico, que constantemente es modificado, la fuente de vida del derecho organizado, con el que constantemente entra en conflicto"; así como que dejara de lado la cuestión del pluralismo jurídico; Sociología del Derecho, Editorial Rosario, Rosario, 1945 (342 p.), p. 129 y 131.

${ }^{94}$ La división del trabajo social, cit., p. 79-80 y 149.

95 R. Aron, Las etapas del pensamiento sociológico. II. Durkheim. Pareto. Weber, Ediciones siglo veinte, Buenos Aires, 1980 (405 p.), p. 30.

${ }_{96}$ A la distinción entre el Derecho represivo y el restitutivo dedicó Durkheim en buena medida el libro primero de La división del trabajo social, cit., p. 57-270; Lecciones de Sociología, cit., p. 84, 167 y 180; Educación como socialización, cit., p. 73.
} 
grande se pregunte por la salud de éste, es decir, que el organicismo suele traer consigo el medicalismo. En el caso de Durkheim resulta patente que así fue, y ya hemos visto distintas dolencias que -a su juiciopodían aquejar a la sociedad. No sólo eso sino que entendió que la misión del político era ocuparse con aquéllas. "El papel del hombre de Estado no es ya empujar violentamente a las sociedades hacia un ideal que le parece seductor, sino que su papel es el de médico: previene el nacimiento de las enfermedades mediante una buena higiene $y$, cuando se declaran, procura curarlas" $^{\prime 97}$. No lo dijo, pero parecía claro que el jurista tenía un trabajo similar, prevenir las dolencias mediante la recomendación y el consejo técnico, y curarlas mediante acuerdos y sentencias. El Derecho, por tanto, funcionaba como medicina preventiva, pero también como terapia a aplicar cuando la enfermedad hubiera aparecido en el cuerpo social. Queda claro por qué el creador del Derecho, como el médico, no puede mandar lo que le venga en gana, es decir, que la teoría de la omnipotencia del legislador es un prejuicio; que las posibilidades de éste, como las del médico, están limitadas ${ }^{98}$.

Por último, conectado con el tema de su fundamento, hay que dejar constancia de la estima en que Durkheim tenía el Derecho ${ }^{99}$. Frente a otro positivismo sociologista que sólo veía en él la pura fuerza, Durkheim creía que no se agotaba así su realidad, que el Derecho era una mezcla de fuerza y autoridad, de violencia y respeto, confirmando así la lectura antes hecha de su teoría de la norma: si nos doblegamos a sus órdenes no es porque esté armado suficientemente, aunque lo esté, sino "porque es objeto de auténtico respeto", dijo ${ }^{100}$. Claro que hablaba del Derecho in genere, porque también podía haberlo injusto, deslegitimado para generar un verdadero deber de obediencia ${ }^{101}$, es decir, que no bastaba con que hubiera reglas, era preciso, además, que fueran justas ${ }^{102}$. La cuestión de la legitimidad, sin embargo, no quedó suficientemente clara. Cuando se refirió a la democracia como forma de gobierno, se preguntó por qué debían cumplirse sus leyes. ¿Porque las quisiéramos? Pero siempre habría minorías que no las querrían. Hacer depender la legitimidad de las leyes de un querer, ya fuera el de la persona interesada, ya el que expresaba un número de votos, era erróneo. "No es porque la hemos hecho, porque ha sido querida por tantos votos por lo que nosotros nos sometemos a ella; es porque es buena, es decir, de acuerdo con la naturaleza de los hechos, porque es todo lo que debe ser, porque tenemos confianza en ella". El respeto sentido por los gobernantes, entonces, era un dato

\footnotetext{
97 Las reglas del método sociológico, cit., p. 91.

98 La educación moral, cit., p. 241.

99 Para Durkheim sin duda el Derecho era un fenómeno respetable, lo "que no es sino una versión del respeto por lo superior, lo social"; J. DE LUCAS, El concepto de solidaridad, Fontamara, México, 1993 (125 p.), p. 65.

${ }^{100}$ Las formas elementales de la vida religiosa, cit., p. 343.

101 En ocasiones, en Durkheim, "el Derecho queda reducido a mera fuerza"; R. COTTERRELL, Emile Durkheim. Law in a Moral Domain, Stanford University Press, Stanford, California, 1999 (276 p), p. 205.

102 La división del trabajo social, cit., p. 478.
} 
fundamental para la buena marcha del Derecho ${ }^{103}$. Los que no quedaban suficientemente claro eran los criterios que servirían para discernir cuál era la naturaleza de la cosa y cuál su degeneración, lo que debe ser y lo que no debe ser. Porque Durkheim, que se adhirió al relativismo cultural, nunca creyó en criterios absolutos de valor: "cada nación concibe a su manera el ideal humano -dijo-, y entre estos ideales no hay uno que goce de una especie de supremacía y de excelencia"104.

\subsection{La teoría penal de Durkheim}

La teoría médica del Derecho hallaba el mejor campo de pruebas en el ámbito penal, razón que explica las muchas referencias que hizo Durkheim al Derecho criminal $^{105}$. Ya en su primera gran obra se refirió a él como el que utilizaba con claridad y precisión castigos definidos para reprimir los crímenes, es decir, las acciones y omisiones que herían sentimientos que se encontraban muy fuertemente grabados en todas la conciencias sanas de una sociedad y que, por tanto, atacaban la misma solidaridad ${ }^{106}$. El delito, por tanto, era delito porque se castigaba, no se castigaba porque fuera delito ${ }^{107}$. La referencia a la sanidad nos recuerda el carácter médico de la teoría penal de Durkheim. Sin embargo, más adelante rectificará lo que había mantenido en un primer momento, y llegará a decir que la existencia de crímenes era normal (lo verdaderamente sorprendente sería que no existieran), constituyendo sólo una anormalidad si pasaban de cierto número. No sólo era perfectamente normal que hubiera delitos, sino que cada tipo de sociedad tenía sus tipos delictivos que le eran propios, conforme a las pasiones que aquejaran a la conciencia colectiva (pues tampoco el crimen era un acto individual llegará a decir- sino el reflejo de la conciencia social en la del

103 Lecciones de Sociología, cit., p. 103-104.

104 La educación moral, cit., p. 261-262.

105 Sobre la teoría penal de Durkheim, valga citar las aportaciones de J. DE LUCAS, "Solidaridad y Derecho penal (Una lectura de Durkheim)", Revista General de Derecho XXVII, 1980, p. 1370-1382; también las de G. ROBLES en Crimen y castigo, cit.

${ }^{106}$ La división del trabajo social, cit., p. 83-101 y 416. Repárese en la acusación que uno de los más importantes teóricos del Derecho del siglo XX, H.L.A. Hart, al hilo de su polémica con Lord Devlin, lanzó sobre Durkheim, cuya doctrina sería un buen ejemplo de la teoría de la desintegración, conectada con el moralismo legal, es decir, afirmaría que la moral establecida es necesaria para que exista la sociedad, la cohesion social, y que por tanto debería ser protegida penalmente; vid. H. L. A. HART, "Social Solidarity and the enforcements of morals" [1967], en H. L. A. HART, Essays in Jurisprudence and Philosophy, Clarendon Press, Oxford, 1.985 (p. 248-262), p. 252-259. Sin embargo, bien puede pensarse que semejante interpretación simplifica y caricaturiza el pensamiento de Durkheim, que no da por buena cualquier pretensión moral, como el mismo Durkheim demostró ante el caso Dreyffus, por ejemplo; vid. S. LUKES y D. PRABHAT, "Durkheim on law and morality: The disintegration thesis", Journal of Classical Sociology 12 (3-4), 2012 (p. 363-383), p. 364, 373-377 y 380-381. Realmente, el proyecto de Durkheim no puede reducirse al comunitarismo, una vez que el individualismo y el liberalismo ha pasado a formar parte de la conciencia colectiva de nuestras sociedades; vid. M. S. CLADIS, $A$ Communitarian Defense of Liberalism. Emile Durkheim and Contemporary Social Theory, Stanford University Press, Standford, California, 1992 (339 p.).

107 Las reglas del método sociológico, cit. p. 59. 
delincuente). Por ejemplo, el homicidio en los países católicos ${ }^{108}$. En semejante tesis -dijo- nada había de subversivo, porque el crimen era normal siempre y cuando fuera castigado. Lo anormal, de nuevo, sería que no se castigara, lo que precisamente traería consigo un aumento de la criminalidad. De hecho, tanto los delitos como las penas eran universales, precisamente porque unos y otras eran, dentro de ciertos límites, normales ${ }^{109}$. Por supuesto que la penalidad sirve para que se produzcan menos delitos $y$, en este sentido, los previene, pero lo fundamental de las penas no es que causen daño o sufrimiento, lo fundamental es que afirman "la regla que la falta ha negado". Durkheim se estaba refiriendo al papel del castigo en la educación de los niños pero resulta aplicable a este otro ámbito de los adultos ${ }^{110}$, y señaló la distancia que media entre aquél y el golpe que recibe el animal que está siendo adiestrado o, lo que es lo mismo, entre la responsabilidad moral y el condicionamiento operante ${ }^{111}$. En cuanto a las recompensas, afirmó que era normal que tuvieran mucho menor peso que los castigos, ya que las acciones conforme a Derecho "no tienen todo su valor más que cuando se realizan sin que el agente haya tenido a la vista una recompensa señalada"112.

Ahora bien, para comprender el concepto de Derecho penal en Durkheim resulta indispensable referirse a la distinción que acuñó entre un Derecho represivo y otro restitutorio, distinción que reenviaba a la otra de solidaridad mecánica y orgánica. Al menos en De la división, la correspondencia entre esos dualismo era fundamental, pues lo que se propuso fue estudiar los diversos tipos de solidaridad atendiendo al signo externo de las normas jurídicas que le eran propias a cada uno: puesto "que el Derecho reproduce las formas principales de la solidaridad social, no tenemos sino que clasificar las diferentes especies del mismo, para buscar en seguida cuáles son las diferentes especies de solidaridad social que a aquéllas corresponden"113. Mientras que el Derecho represivo correspondía al lazo de la solidaridad mecánica, y cada vez más disminuía su importancia, el restitutorio era el propio de la orgánica, y últimamente aumentaba ${ }^{114}$. Ese principio fue el que guío al Durkheim criminólogo, autor de un artículo fundamental para la antropología del Derecho penal, "Deux lois de I'evolution pénale", la de las variaciones cuantitativas y, una concreción de ésta ${ }^{115}$, la de las variaciones cualitativas del castigo penal. La primera rezaba así: "La intensidad del castigo es mayor en la medida en que la sociedad pertenece a un tipo menos desarrollado y al

\footnotetext{
108 Lecciones de Sociología, cit., p. 114.

109 Las reglas del método sociológico, cit., p. 14 y 84; El suicidio, cit., p. 403-405.

110 Que la misma tesis es aplicable al Derecho Penal resulta obvio, cuando ya había afirmado tajantemente que "la función de la pena es mantener intacta la cohesión social": La división del trabajo social, cit., p. 127.

${ }^{111}$ La educación moral, cit., p. 166.

112 Ibidem, p. 193.

113 La división del trabajo social, cit., p. 45 y 79.

114 Ibidem, p. 243.

115 Vid. S. SPITZER, "Punishment and Social Organization: A Study of Durkheim's Theory of Penal Evolution", Law and Social Review 9, 1.975, 613-637, p. 617.
} 
grado en que el poder central tiene un carácter más absoluto"116. Llegados a Beccaria, a quien citaba respetuosamente, formulaba la segunda: "El castigo que implica la privación de la libertad y solamente de eso por períodos de tiempo que varían con la gravedad del crimen, tiende crecientemente a volverse el tipo normal de sanción" ${ }^{117}$.

Conforme a su medicalismo penal, Durkheim optó por una postura humanista que traía consigo la crítica al sistema penitenciario: a "la promiscuidad de las prisiones", donde reina "un sordo espíritu de desorden y de rebelión"; a las legislaciones caracterizadas por la excesiva dureza o por usar pocos tipos de pena y olvidarse, además, de las medidas alternativas; a los Derechos que nada les importa la dignidad del ser humano ${ }^{118}$.

\subsection{Otras ideas de Durkheim sobre el Derecho}

Decir otras ideas de Durkheim sobre el Derecho puede dar a entender que también se ocupó con aspectos más técnicos o con cuestiones puntuales, cuando realmente quisiera referirme aquí sobre todo a su concepción de los juristas y de la ciencia jurídica, que si bien quedó desdibujada, puede perfilarse más por medio de la comparación que pareció establecer entre los juristas y los educadores, entre la Jurisprudencia y la pedagogía.

Durkheim apuntó los requisitos que -a su juicio- debía satisfacer un conocimiento para que pudiera ser calificado de científico: 1) tener un objeto que pudiera someterse a observación y que pudiera ser delimitado "en el conjunto de la realidad"; 2) que ese objeto fuera homogéneo, es decir, que estuviera constituido por hechos que pudieran ser clasificados dentro de la misma categoría; y 3) que el único objetivo de ese estudio fuera el conocimiento. En el caso de lo que se suele entender por ciencia jurídica, sin embargo, parecía que ésta se encontraba dirigida a la práctica, es decir, que no tenía por finalidad tanto "expresar la naturaleza de las cosas determinadas", lo que hacía la ciencia, cuanto "dirigir la acción", establecer lo que debe ser. Aunque tuviera menos de ciencia que de arte, algo tenía de una y de otro, y por eso Durkheim creyó que lo mejor sería denominarla teoría práctica, como a la pedagogía, la teoría política, etc. ${ }^{119}$. Aunque esa teoría práctica del Derecho era "un factor de su desarrollo", es decir, que las ideas que se tienen sobre lo que es y debe ser el Derecho se integran en él y lo conforman ${ }^{120}$, en realidad la verdadera ciencia del Derecho no era la que se tenía por tal, sino la que denominó física del Derecho, esto es, la sociología del Derecho, que se dedicaba al estudio tanto de las causas y de los fines de las normas jurídicas, cuanto de su funcionamiento en la sociedad, para lo que se valía

\footnotetext{
${ }^{116}$ E. DURKEHIM, "Dos leyes de la evolución penal" [1900] Delito y Sociedad. Revista de Ciencias Sociales 13, 1999, 71-90, p. 71.

117 " Ibidem, p. 79.

118 La educación moral, cit., p. 186-189.

${ }^{119}$ Educación y sociología, cit., p. 74-75; Las reglas del método sociológico, cit., p. 52.

${ }^{120}$ Las reglas del método sociológico, cit., p. 21.
} 
de la etnografía, la historia y la estadística ${ }^{121}$. Esto, que sólo quedó apuntado en Les régles, donde también señaló que el estado entonces actual de la sociología del Derecho era penoso ${ }^{122}$, se hizo expreso en las Lecons de sociologie ${ }^{123}$. En cuanto al jurista, nada dijo de él pero le son aplicables -creo- las características que correspondían al educador, pues tanto el ministerio de uno como el del otro tenían que estar revestidos de autoridad, una cualidad que simbolizaba que "el deber es el deber". Como el sacerdote, que interpreta las ideas religiosas, el maestro y el jurista interpretan las ideas morales de la sociedad y, por tanto, tienen que creer en ellas para poder transmitir el respeto que merecen, respeto "del deber y de la razón"124.

Otras dos cuestiones que merecen ser apuntadas en este apartado son las relativas al proceso y el Derecho procesal, por una parte, y al Derecho primitivo, por otra. En cuanto a la primera, porque cabe aplicarle para su esclarecimiento las tesis que mantuvo respecto a los ritos en el ámbito religioso. Así, los procesos no se seguían en cualquier sitio sino en "templos y santuarios", es decir, en un espacio sagrado separado del escenario donde se desarrollaba la vida ordinara o profana, y su función era la misma que la de los ritos religiosos, reafirmar cada cierto tiempo el grupo social ${ }^{125}$. En este marco, el respeto que inspiraban los jueces, funcionarios "investidos de altas funciones sociales", era similar -decía- al respeto religioso, y así se refleja en el Derecho procesal: "uno se mantiene a distancia de un alto personaje; le aborda con precaución y, al hablar con él, emplea otro lenguaje y otros gestos que los que le sirven para comunicarse con el común de los mortales. El sentimiento experimentado en tales circunstancias está tan próximo al sentimiento religioso, que muchos pueblos los confunden. Para explicar la consideración de la que gozan los príncipes, los nobles o los jefes políticos, se les ha atribuido a veces un carácter sagrado. Por ejemplo, en Melanesia y en Polinesia se dice de un hombre influyente que tiene mana, y su influencia se atribuye a dicho mana"126. Pues bien, al igual que toda religión se componía de "representaciones y de prácticas rituales", creo que para Durkheim el Derecho también se componía de representaciones, de normas, y de prácticas rituales, de procesos ${ }^{127}$, aspectos que no podían desgajarse para llevar a cabo su estudio, pues eran solidarios entre sí128.

En cuanto al Derecho primitivo, si bien Durkheim no le dedicó un trabajo en concreto, se refirió a él en diversas ocasiones, aportando tesis que a lo largo del siglo XX a veces serían aceptadas como obviedades $\mathrm{y}$, en

\footnotetext{
121 Téngase en cuenta que, al referirse a un caso concreto, el del Derecho penal, pareció afirmar que su ciencia era la criminología: Las reglas del método sociológico, cit., p. 59.

122 Ibidem, p. 21, 45 y 52-53.

${ }^{123}$ Lecciones de Sociología, cit., p. 7.

${ }^{124}$ Educación y sociología, cit., p. 70-72.

125 Las formas elementales de la vida religiosa, cit., p. 492 y 608.

${ }^{126}$ Las formas elementales de la vida religiosa, cit., p. 352.

127 La distinción recuerda aquella otra que se puso de moda en Estados Unidos a principios del siglo XX, y que utilizaron Pound y Llewellyn: Law in books y Law in actions. ${ }^{128}$ Las formas elementales de la vida religiosa, cit., p. 179.
} 
cambio, en otras ocasiones, negadas duramente. En De la división dijo que parecía que en las sociedades salvajes el Derecho se identificaba con el Derecho represivo ${ }^{129}$ (lo que le valió las críticas de los antropólogos, por cierto $\left.{ }^{130}\right)$. En Les formes élémentaires, que su fundamento tenía carácter religioso, de lo que se tratará más adelante, y que el formalismo jurídico tenía su origen en el formalismo religioso ${ }^{131}$. Además, en este último libro, el más propiamente etnológico de los suyos, argumentó a favor de la antropología cultural, y sus razonamientos son punto por punto aplicables a la antropología del Derecho. 1) Su finalidad no es el estudio de lo raro y singular, sino la naturaleza de los fenómenos sociales: "aunque es útil saber en qué consiste tal o cual religión en concreto, aún importa más investigar lo que es la religión en general". 2) El hecho de que su objeto, las sociedades primitivas y sus instituciones, presenten la realidad social en su forma más simplificada, trae consigo asombrosas revelaciones que sirven para renovar todas las ciencias sociales. 3) Para su comprensión, es fundamental conocer el origen de las instituciones para luego analizar su desarrollo hasta el momento presente ${ }^{132}$. 4) En cuanto al método, la etnología requiere un punto de vista externo, etic, aunque también hay que tener en cuenta el interno, emic, así como un análisis estructural y funcional al mismo tiempo: las razones del nativo "pueden ser erróneas, y lo son en la mayoría de los casos, pero no por ello dejan de existir razones verdaderas, y corresponde a la ciencia la tarea de descubrirlas"133. Este último postulado no significa que Dukheim fuera transigente con el etnocentrismo, el error de sustituir "con nuestras ideas europeas las que tiene el primitivo sobre el mundo y la sociedad", lo que significaba una defectuosa comprensión de la relidad social, y jurídica, que fuera, como cuando se decía que los salvajes carecían de moral simplemente porque era distinta de la del observador ${ }^{134}$.

\subsection{El fundamento del Derecho o el sentido de la vida social}

Pero probablemente más interesante que el concepto de Derecho que nos legó Durkheim, sea el del fundamento que trató de otorgarle. Mientras alrededor del credo marxista se organizaba un movimiento obrero agresivo, que despreciaba el mundo jurídico por encubridor de intereses inconfesables y proclamaba abiertamente que el orden del Derecho carecía de fundamento, Durkheim vino a afirmar lo contrario, pero no

\footnotetext{
${ }^{129}$ La división del trabajo social, cit., p. 163.

130 Porque en las sociedades primitivas no sólo habría Derecho represivo, evidentemente; vid. M. CLARKE, "Durkheim's Sociology of Law", Journal of Law and Society 3, 1.976, p. 247-254, p. 251; K. THOMPSON, Emile Durkheim, Ellis Horwood y Tavistock Publications, New York, 1.982, p. 89-90.

${ }^{131}$ Las formas elementales de la vida religiosa, cit., p. 80; Lecciones de sociología, cit., p. 174.

132 Téngase en cuenta que las instituciones jurídicas pueden "evolucionar indefinidamente". Durkheim lo dice en relación a la propiedad, pero es aplicable a cualquiera otra: Lecciones de Sociología, cit., p. 201.

${ }^{133}$ Las formas elementales de la vida religiosa, cit., p. 27-39.

${ }^{134}$ La división del trabajo social, cit., p. 284; Las reglas del método sociológico, cit., p. 63; Las formas elementales de la vida religiosa, cit., p. 242.
} 
porque este o aquel ordenamiento no pudieran ser ilegítimos, sino porque, en general, el Derecho tenía asignada una misión de especial importancia, por más que a veces se desviara de su cometido. No dejaba de ser enigmático: el Derecho resultaba estimable porque era necesario. Lo que también resulta curioso en lo tocante a la fundamentación del Derecho es que -a mi juicio- el trabajo fundamental a este respecto es el último voluminoso que publicó en vida, Les formes élémentaires de la vie religiense, y sin embargo, cuando se apuntan las obras que Durkheim dedicó al estudio del fenómeno jurídico, siempre se silencia ésta, quizás porque se piensa que se dedica únicamente a la antropología de la religión, cuando también es fundamental para la del Derecho y para la teoría jurídica en general ${ }^{135}$. Así todo, antes de escribir esta última obra, Durkheim ya había dejado clara su posición al respecto de la justificación del Derecho.

En la tríada compuesta por De la división, Las régles y Le suicide, ya expuso la doctrina fundamental a este respecto, la del sentido de la vida social. ¿Por qué debe ser cualquier norma si no porque debe ser la vida social? En efecto, quien busque una primera norma que otorgue fundamento a las demás, tiene que admitir que si no debe ser la sociedad, entonces nada debería ser, que no habría ningún deber. Con sus términos, que "el hecho de la asociación es el más obligatorio de todos", y que por eso "es la fuente de todas las demás obligaciones"136. Si, como ya vimos, es la misma sociedad la que crea las reglas, y lo hace adaptándolas a sus propias necesidades, la única razón para llevar a cabo lo que las normas ordenan, esto es, para que deba ser lo que la norma dice que debe ser, es que haya una norma previa, lógicamente anterior, que establezca que debe ser la sociedad. Tal vez esta norma que exige la vida social permanezca "difusa" o, con otras palabras, tácita, pero no por eso es menos real ${ }^{137}$, pues es un hecho -dice Durkheim- que los nacionales de un país o, mejor, quienes pertenecen a una sociedad cualquiera "procuran que no se destruya y que prospere" ${ }^{\prime 138}$. Evidentemente, no es un dato fáctico sin más, pues quienes así actúan tienen sus razones para hacerlo. De hecho Durkheim vino a definir el sentido de la vida como "la razón para soportar con paciencia las miserias de la vida" o "la razón de estar en la vida" o "las razones de vivir" o, también, lo que hace que la vida merezca la pena. Que esto es así, es decir, que resulta natural que la vida tenga sentido, se demuestra - dice- porque a veces aparecen corrientes patológicas de pensamiento que se dedican a afirmar "que la vida no tiene sentido" ${ }^{\prime 139}$. Sentido de la vida no significa que vivamos, ni que queramos

\footnotetext{
135 En la recopilación de textos de Durkheim que versan sobre el Derecho, editado por Steven Luckes y Andrew Scull, E. Durkheim, Durkheim and the Law, Oxford, Martin Robertson, 1.983 (241 p.) dicen haber reunido los más significativos, pero ninguno de ellos pertenece a Les formes élémentaires. Por lo demás, vid. la nota no 2.

${ }^{136}$ Las reglas del método sociológico, cit., p. 117.

137 El suicidio, cit., p. 345.

${ }^{138}$ La división del trabajo social, cit., p. 124.

${ }^{139}$ El suicidio, cit., p. 215, 219-221 y 277.
} 
vivir, sino que "debemos querer vivir"140. Pues bien, si ni el hombre, ni la sociedad, ni la humanidad debieran vivir, esto es, si la vida no tuviera sentido, ninguna otra norma lo tendría. Claro que en Durkheim parece distinguirse con bastante claridad entre el sentido de la vida individual y el de la social, entre las razones que un individuo tiene para vivir y las que tiene una sociedad, que al fin y al cabo es un individuo sui generis. No sólo las de aquél dependen de las de ésta, en el sentido de que constituyen una parte importante de su naturaleza moral, sino que son precisamente las razones de la asociación las que justifican el Derecho o cualesquiera otras normas sociales, pues precisamente éstas están establecidas en bien de aquélla. No sólo es natural que la sociedad viva, sino que también lo es reconocer que debe seguir viviendo, y por eso debe haber normas, normas que deben ser acatadas. Mantener lo contrario es tanto como considerar deseable el caos, cuando es evidente que "una tal anarquía constituye un fenómeno morboso", que atenta "contra el fin mismo de toda sociedad, que es el de suprimir, o cuando menos moderar, la guerra entre los hombres, subordinando la ley física del más fuerte a una ley más elevada"141. Durkheim creyó ver un ejemplo que confirmaba su tesis en el Derecho primitivo, un Derecho que, amén de represivo, era sagrado. ¿Qué autoridad sería capaz de otorgar mayor legitimación al Derecho que Dios mismo? Evidentemente, ninguna, y por eso se cree que la mayor autoridad imaginable es la que ordena obedecer el Derecho ${ }^{142}$, porque éste es tan importante para la sociedad que debe ser guardado contra toda violación, aunque de hecho se quebrante ${ }^{143}$. Pero a la religiosidad del Derecho, a su carácter sagrado, se referirá en extenso más adelante.

En Les formes elementaires, la principal tesis que defendió Durkheim constituía una teoría de la religión: "la fe religiosa tiene su origen en la sociedad", es más -venía a decir-, la fuerza religiosa no era otra cosa que la fuerza de la sociedad, y los dioses, la sociedad misma hipostasiada ${ }^{144}$. Pero en la misma obra también apuntó una teoría antropológica del Derecho, cuando reconoció que el origen de éste, y de otras muchas creaciones culturales, se hallaba en la religión: "las técnicas y las prácticas más diversas, ya aseguren el funcionamiento de la vida moral (como el derecho, la moral o las bellas artes) o ya sirvan a la vida material (como las ciencias de la naturaleza y las técnicas industriales) se han derivado, directa o indirectamente, de la religión"145. Curiosamente, en la explicación del origen del mundo jurídico se hallaba su justificación.

\footnotetext{
${ }^{140}$ La división del trabajo social, cit., p. 42.

141 Ibidem, p. 3.

142 Ibidem, p. 166.

${ }^{143}$ En un artículo de 1.898 dijo explícitamente que las normas jurídicas eran obligatorias, y que esa obligación era precisamente "la prueba de que estos modos de obrar y de pensar no son obra del individuo, sino que emanan de una autoridad moral que lo sobrepasa, imaginada místicamente bajo la forma de un dios, o bien concebida de una manera más temporal y más científica"; Educación como socialización, cit., p. 73.

${ }^{144}$ Las formas elementales de la vida religiosa, cit., p. 342, 364 y 672.

145 Ibidem, p. 368.
} 
A su juicio, la totalidad de lo real podía someterse a una clasificación, radical y bimembre, implicada en todas las creencias religiosas: la realidad podía ser sagrada o profana. Ambas ideas se requieren mutuamente, pues las cosas sagradas son aquéllas protegidas y separadas de las cosas profanas por prohibiciones y sanciones, pero sin que se pueda establecer un criterio más concreto de demarcación ${ }^{146}$. A su vez, las cosas sagradas podían ser benéficas o maléficas, puras o impuras, según que fueran bienhechoras o malvadas ${ }^{147}$. Pues bien, el Derecho cae dentro de las cosas sagradas y bienhechoras para el hombre, y, al igual que a otros seres sagrados, no sólo se le teme sino que también se le respeta y se le venera con gratitud ${ }^{148}$. No se piense que esto únicamente ocurre en las creencias primitivas, pues acaso "para el cristiano, ¿no es Dios Padre el garante del orden físico a la vez que el legislador y el juez de la conducta humana?"149. Pero si la religión no es otra cosa que el velo que oculta la misma vida social, resulta que es ésta la verdadera legisladora, una legisladora dotada de una razón "que hace que aceptemos confiadamente sus sugerencias", pues la cooperación propia de la vida en común así lo requiere. El Derecho, entonces, es necesario, pero su necesidad es moral $y$, por tanto, es obligatorio ${ }^{150}$.

Posteriormente Durkheim seguirá sosteniendo la misma tesis. En Éducation et sociologie afirmó que si había normas era porque la sociedad resultaba deseable, porque debía existir ${ }^{151}$. En L'Education morale lo expresó con gran plasticidad: si la vida no debe ser, nada debe ser. Claro que -advirtió- se debe vivir, pero no porque sí, sin más, sino en virtud de un fin más alto, fin que no puede ser otro que el propio grupo, con lo que la adhesión a éste resultaba ser "el deber por excelencia"152. Volvió a asegurar que desde siempre las sociedades habían visto la ley como el producto de algún ser divino, aunque tras él, como ya sabemos, se escondía "el sentido de la vida en grupo", grupo que -repitió- era "digno de ser amado" ${ }^{153}$. Por fin, en Lecons de sociologie volvió a recordar que si en las concepciones populares las leyes emanan de la divinidad es porque tienen una importancia asombrosa para la vida social, no sólo para los individuos sino para "la colectividad nacional". Expresada de forma sintética, otra vez la teoría de la religión dejaba ver el fundamento del Derecho: "las religiones, aun las más groseras, no son, como se lo ha

\footnotetext{
146 Las formas elementales de la vida religiosa, cit., p. 81-90. Esta clasificación sagrado/ profano sería criticada por Bronislaw Manlinowski, nada menos, pues no sería universal; no podría aplicarse a los pueblos más primitivos; vid. Recensión de "Les formes élémentaires de la vie religieuse. Le système totémique en Australie", Folklore 24, p. 525-531p. 526-527.

147 Las formas elementales de la vida religiosa, cit., p. 640-644.

148 Evidentemente, no sólo el Derecho sino que la moralidad toda revestía un carácter sagrado, así lo afirmó en un artículo de la época: La science sociale et l'action, cit., p. 327.

${ }^{149}$ Las formas elementales de la vida religiosa, cit., p. 317-318.

150 Ibidem, p. 53.

${ }^{151}$ Educación y sociología, cit., p. 62.

152 La educación moral, cit., p. 42, 61, 71 y 75.

153 Ibidem, p. 149, 232 y 243.
} 
creído a veces, simples fantasmagorías que no corresponden a nada en la realidad. Sin duda no expresan las cosas del mundo físico tal como son; como explicación del mundo, carecen de valor. Pero expresan, en forma simbólica, necesidades sociales, intereses colectivos" ${ }^{\prime 154}$.

Tras este repaso de los textos de Durkheim, parece que ya nada queda por decir, que la moralidad y el Derecho tenían por fin último la salvaguarda de la sociedad, que ahí se acababa su reino, que en ella se encontraba tanto su origen como su fin, tanto su explicación como su justificación, y sin embargo... Aunque no fue tan claro ni le dedicó tanto espacio, parecía que tras ese ideal societario había algo más, parecía que tras el peldaño de la sociedad aparecía un nuevo escalón que ya sería definitivo, el del género humano. Desde luego, no estaba demostrada la imposibilidad de que la humanidad en su conjunto pudiera constituir una sola sociedad pero, aunque así fuera, se trataba de una sociedad en potencia de la que todos los hombres formarían parte ${ }^{155}$. Sin embargo, ¿no había contradicción entre el ideal de la patria, que Durkheim tanto proclamó, y el de la humanidad? No necesariamente, pues ambos podían y debían confundirse. "Que el Estado no tenga otro fin -dijo- que el hacer de sus ciudadanos hombres, en el sentido total de la palabra, y los deberes cívicos no serán sino una forma más particular de los deberes generales de la humanidad"156. En último término, el fundamento de cualquier orden normativo, también el del Derecho, se hallaba en "la realización progresiva de la idea de humanidad"157; para empezar, por tanto, en la supervivencia del género humano.

Mas por lo que pudiera pensarse, hay que decir que Durkheim nunca se consideró partidario del Derecho natural; es más, siempre se refirió al Ius Naturae con aversión, expresando su repudio. Definió el iusnaturalismo como aquella teoría "según la cual el derecho individual se deriva de la naturaleza individual, se lo representa como algo universal, como un código que no [sic] puede establecerse de una vez por todas y que vale para todos los tiempos como para todos los países". Acto seguido lo tachó "de un simplismo artificial". Por ejemplo, si Spencer creía que era natural el concepto de contrato, que consiste en cambiar cosas de igual valor, resulta que el valor de las cosas depende de cada sociedad, es decir, que nunca se valoran igual. Si Kant afirmaba que a la persona debía reconocérsele autonomía, ocurría que en términos absolutos era imposible, y si sólo hablaba en términos relativos entonces la determinación quedaba otra vez en manos de la sociedad que fuera. En fin, los derechos no eran naturales sino, al contrario, culturales, esto es, "creados y organizados por el Estado"158. Si se puede distinguir entre una teoría maximalista y otra minimalista del Derecho Natural, la primera fracasaría estrepitosamente por no poder verificarse, mientras que la

\footnotetext{
${ }^{154}$ Lecciones de Sociología, cit., p. 20, 70 y 151.

155 La división del trabajo social, cit., p. 403 y 475-476.

156 Lecciones de Sociología, cit., p. 73.

157 La educación moral, cit., p. 78-81.

${ }^{158}$ Lecciones de Sociología, cit., p. 60 y 66-67.
} 
segunda sería intrascendente porque ninguna moral se compone sólo de principios generales, principios que se reducen "a una cosa vaga y esquemática que deja a una distancia infinita los hechos que se trata de explicar". Si lo que se quiere decir con el Derecho natural es que existen fenómenos sociales que se repiten en las distintas sociedades, es cierto, pero también que nunca son iguales, que en cada una de ellas adquieren su peculiar fisonomía ${ }^{159}$. Los iusnaturalismos, en fin, parecían tener algo de pensamiento primitivo, pues éste explicaba los fenómenos naturales en virtud de causas personales. "Era sólo una metáfora, pero se la tomó al pie de la letra", dijo Durkheim. Además, apelar a la naturaleza humana para explicar o justificar el Derecho era errado, porque en ningún caso lo general basta para dar cuenta de lo particular ${ }^{160}$.

En otras ocasiones pareció defender tesis que pudieran hacernos creer lo contrario, como cuando reconoció que la moralidad tenía una parte inmutable y otra cambiante ${ }^{161}$, o como cuando vino a admitir la figura del idiota moral ${ }^{162}$, pero no era necesariamente así, pues lo inmutable seguiría sin poder explicar ni justificar lo cambiante, y el deficiente moral lo sería con relación a una sociedad determinada, esto es, a una moral determinada. Sin embargo ya hemos visto que para Durkheim hay alguna norma natural; al menos la que ordena la supervivencia de la sociedad, pues difícilmente se puede decir que es artificial. En todo lo demás Durkheim defendía el relativismo cultural, pero no en este punto, pues parecía intelectualmente ofensivo pretender que la supervivencia, "una de nuestras tendencias fundamentales" ${ }^{163}$, no era natural. Me refiero, claro, a la supervivencia de la sociedad, no sólo a la de los individuos. Ahora bien, habrá quien argumente que se trataba de un instinto, de una tendencia, de un hecho; en absoluto de norma alguna. En efecto pero, si la vida tiene sus exigencias, "¿cómo no ver que, suponiendo que el hombre quiera vivir, una operación muy sencilla transforma inmediatamente las leyes que aquélla establece en reglas imperativas de conducta?"164. Entendiéndolo en sus justos términos, mirado desde cierto punto de vista (recuérdese que se trata de un defensor del relativismo cultural), Durkheim también era iusnaturalista, al menos porque identificaba lo natural con lo necesario ${ }^{165}$ (y ya lo vimos, al menos a veces, lo necesario con lo obligatorio). Por lo demás, téngase en cuenta que, al menos en algunos momentos de su obra, apela con cierta insistencia a la naturaleza de las cosas como argumento definitivo, y que parece identificar esa naturaleza con la razón, una razón que podría justificarse lógicamente, sin

159 Las reglas del método sociológico, cit., p. 119 y 140-141. Como agudamente señala Cotterrell, que Durkheim niegue la existencia del Derecho natural no significa que niegue "la existencia de valores morales universales"; Emile Durkheim. Law in a Moral Domain, cit., p. 254.

160 Las formas elementales de la vida religiosa, cit., p. 143 y 565.

161 Las reglas del método sociológico, cit., p. 62.

162 La educación moral, cit., p. 42.

163 Las reglas del método sociológico, cit., p. 139.

164 La división del trabajo social, cit., p. 42.

165 Lecciones de Sociología, cit., p. 61. 
necesidad de acudir a ningún ser divino; una razón que reconoce, aun limitadamente, que es lo que debe $\operatorname{ser}^{166}$.

\section{CONCLUSIÓN}

La lectura que Durkheim nos legó del fenómeno jurídico lo convierte en un clásico imprescindible de la teoría del Derecho, al que otorgó sentido, frente a los que afirman una razón de ser inmanente al propio ordenamiento, en el marco de una amplia teoría social, de tal forma que así el Derecho no puede ser comprendido independientemente de la sociedad en la que existe. Su importancia para la sociología jurídica y su influjo en las teorías sociologistas del Derecho han sido enormes. Eso no significa que Durkheim siempre tenga razón, evidentemente; es más, representa una tendencia idealista y armonicista que por sí sola ofrece una visión demasiado optimista del Derecho, y que debe ser compensada por otra que sea realista y conflictualista. En el término medio está la virtud.

\section{BIBLIOGRAFÍA}

R. ARON, Las etapas del pensamiento sociológico. II. Durkheim. Pareto. Weber [1967] (trad. por A. Leal: Les étapes de la pensé sociologique), Ediciones siglo veinte, Buenos Aires, 1980, 405 p.

M. CLARKE, "Durkheim 's Sociology of Law", Journal of Law and Society 3, 1976, p. 247-254.

R. COTTERRELL, Emile Durkheim. Law in a Moral Domain, Stanford University Press, Stanford, California, 1999, 276 p.

J. DE LUCAS, "Solidaridad y Derecho penal (Una lectura de Durkheim)", Revista General de Derecho XXVII, 1980, p. 1370-1382.

J. DE LUCAS, El concepto de solidaridad, Fontamara, México, 1993, 125 p.

E. DURKHEIM, Recensión de "Antonio Labriola, Essais sur la conception materialiste de I'histoire. Paris. Giard et Brière, 318 p.", Revue Philosphique 44, 1897, p. 645-651.

E. DURKHEIM, La división del trabajo social [1893] (trad. por C.G. Posada: De la División du Travail Social), Akal, Madrid, 1995, 491 p.

E. DURKHEIM, Las reglas del método sociológico [1895] (trad. por L.E. Echevarría: Les régles de la méthode sociologique), Morata, Madrid, $1984,159 \mathrm{p}$.

E. DURKHEIM, El suicidio [1897] (trad. por ¿?: Le suicide: étude de sociologie), Akal, Madrid, 1995, $450 \mathrm{p}$.

E. DURKHEIM, Las formas elementales de la vida religiosa [1912] (trad. por A. Martínez: Les formes élémentaires de la vie religiense), Alianza, Madrid, 1993, 698 p.

E. DURKHEIM, Educación y sociología [1922] (trad. por J. Muls: Éducation et sociologie), Altaya, Barcelona, 1999, $188 \mathrm{p}$.

E. DURKHEIM, La educación moral [1925] (trad. por M.L. Navarro: L'Education morale), Losada, Buenos Aires, 1947, 264 p.

${ }^{166}$ La educación moral, cit. p. 17, 27 y 113-115. 
E. DURKHEIM, 1.950/1.966: Lecciones de Sociología (Física de las costumbres y del Derecho) [1950] (trad. por D. Maldavsky: Lecons de sociologie: physique des moeurs et du droit), Schapire, Buenos Aires, 1974, 205 p.

E. DURKHEIM, La science sociale et I'action, Presses Universitaires de France, Paris, 1970, $334 \mathrm{p}$.

E. DURKHEIM, Durkheim and the Law (S. Lukes y A. Scull, eds.), Martin Robertson, Oxford, 1983, 241 p.

E. DURKHEIM, "Dos leyes de la evolución penal" [1900] (trad. por Mónica Escayola Lara: "Deux lois de I'evolution pénale"), Delito y Sociedad. Revista de Ciencias Sociales 13, 1999, p. 71-90.

E. DURKHEIM, Educación como socialización (trad. por A. Ortiz García), Sígueme, Salamanca, 1976, 274 p.

E. EVANS-PRITCHARD, Historia del pensamiento antropológico [1980] (trad. por I. Vericat: A History of Anthropological Thought), Cátedra, Madrid, 1987, $265 \mathrm{p}$.

D. GARLAND y P. YOUNG (eds.), The Power to Punish. Contemporary Penality and Social Analysis, Heinemann, London, 1983, 238 p.

G. GURVITCH, Sociología del Derecho (trad. por A Romera), E. Rosario, Rosario, 1945, 342 p.

M. HARRIS, El desarrollo de la teoría antropológica. Una historia de las teorías de la cultura [1968] (trad. por R. Valdés: The rise of anthropological theory. A history of theories of culture), siglo veintiuno, Madrid, 1987, 690 p.

H. L. A. HART, "Social Solidarity and the enforcements of morals" [1967], en H. L. A. HART, Essays in Jurisprudence and Philosophy, Clarendon Press, Oxford, 1985, p. 248-262.

R. A. JONES, Emile Durkheim. An Introduction to Four Major Works, Sage Publications, USA, 1986, $165 \mathrm{p}$.

E. LAMO DE ESPINOSA, 1.980: "Social and Legal Order in Sociological Functionalism", Contemporary Crises 4, 1980, p. 43-76.

R. H. LOWIE, Historia de la etnología [1937] (trad. por P. Kirchhoff: $A$ History of Ethnological Theory), FCE, México, 1981, 355 p.

S. LUKES, Emile Durkheim. Su vida y su obra [1973] (trad. por A. Cardín e I. Martínez: Émile Durkheim. His life and work), Centro de Investigaciones Sociológicas, Madrid, 1984, 669 p.

S. LUKES y D. PRABHAT, "Durkheim on law and morality: The disintegration thesis", Journal of Classical Sociology 12 (3-4), 2012, p. 363-383.

B. MALINOWSKI, Recensión de "Les formes élémentaires de la vie religieuse. Le système totémique en Australie", Folklore 24, p. 525531.

R. MARRA, Il diritto in Durkheim. Sensibilitá e riflessione nella produzione normativa, Edizioni Scientifiche Italiane, Napoli, 1986, 198 p.

R. NISBERT, La formación del pensamiento sociológico [1966] (trad. por E. Molina: The Sociological Tradition), Buenos Aires, Amorrortu editores, 1977 (2 vols.) 
E. OSIPOVA, "La sociología de Emile Durkheim" [1979] (trad. del ruso por I. Pozo), en VARIOS, Historia de la sociología del siglo XIXcomienzos del XX, Editorial Progreso, Moscú, 1989, p. 207-258.

A. PODGÓRECKI y Ch. WHELAN (ed.), Sociological Approaches to Law, Croom Helm, London, 1981, 251 p.

L. RECASÉNS SICHES, "Balance sobre Durkheim", en Revista Mexicana de Sociología 21, 3, 1959, p.875-891.

G. ROBLES, Crimen y castigo (Ensayo sobre Durkheim), Civitas, Madrid, 2001, 132 p.

B. ROSHIER y H. TEFF, 1.980: Law and Society in England, Tavistock Publications, London, $1980258 \mathrm{p}$.

S. SPITZER, "Punishment and Social Organization: A Study of Durkheim 's Theory of Penal Evolution", Law and Social Review 9, 1975, p. 613637.

K. THOMPSON, 1.982: Emile Durkheim, Ellis Horwood y Tavistock Publications, New York, 1982, 179 p.

S. VILLENEUVE, "Durkheim. Reflexions sur la méthode et sur le droit", Archives de Philosophie du Droit XIV, 1969, p. 237-255.

K. H. WOLF (ed.), Emile Durkheim, 1.858-1.917. A Collection of Essays with Translations and Bibliography, The Ohio State University Press, Columbus, $1960,463 \mathrm{p}$. 